\title{
PERANCANGAN WEBSITE PENERIMAAN SISWA BARU DENGAN MENGGUNAKAN METODE WATERFALL
}

\author{
Inda Anggraini \\ Teknik Informatika, Sekolah Tinggi Teknologi Pagaralam \\ Jalan Masik Siagim No.75 Simpang Mbacang Kec.Dempo Tengah Kota Pagaralam Sumatera Selatan \\ E-Mail : indaanggraini@gmail.com
}

\begin{abstract}
Widespread technological developments make organizations, corporations and institutions compete in using technology to achieve their expected goals. The purpose of the organization, especially the institution of education is to get learners with the criteria to become learners. Admission New students are the selection process of prospective new Students to get prospective students according to the criteria that have been determined by the school to become students. The purpose of this paper is to design and build the website of the New Student Admission System (PSB) at Madrasah Tsanawiyah Negeri (MTSN) Jambat Balo by using the PHP programming language (Hypertext PreProcessor) and MySQL as the Database tool. The method used is the methodology of SDCL Waterfall System development (Waterfall) is often also called linear sequential model (sequential linear) with the stages of analysis, design, programming code, testing, and support or maintenance (maintenance). With this system Is expected to improve the service process acceptance of new students and can facilitate the committee in providing services for prospective students to support the success of a school in achieving its goals.
\end{abstract}

Keywords: website, PSB, PHP (Hypertext PreProcessor), Waterfall.

\begin{abstract}
Abstrak
Perkembangan teknologi yang meluas membuat organisasi, perusahaan dan juga institusi berlomba dalam menggunakan teknologi untuk mencapai tujuan yang diharapkan. Tujuan organisasi terutama instansi pendidikan tersebut adalah untuk mendapatkan peserta didik sesuai dengan kriteria untuk menjadi peserta didiknya. Penerimaan Peserta didik baruadalah proses menyeleksi calon Siswa untuk mendapatkan peserta didik sesuai dengan kriteria yang telah ditentukan oleh sekolah untuk menjadi Siswa didiknya. Penelitian ini bertujuan untuk membangun website Penerimaan Siswa Baru (PSB) pada Madrasah Tsanawiyah Negeri (MTsN) Jambat Balo dengan menggunakan bahasa pemrograman PHP (Hypertext PreProcessor) dan MySQL sebagai Database tool. Metode pengembangan yang peneliti gunakan adalah SDCL Air Terjun (Waterfall) yang disebut juga model sekuensial linier (sequential linier) Dengan adanya sistem ini diharapkan dapat meningkatkan proses pelayanan penerimaan Siswa baru dan dapat mempermudah panitia dalam memberikan pelayanan bagi calon Siswa sehingga dapat mendukung keberhasilan suatu sekolah dalam mencapai tujuannya.
\end{abstract}

Kata Kunci : website, PSB, PHP (Hypertext PreProcessor), Waterfall.

\section{Pendahuluan}

ini juga punya kelemahan, karena menuntut cost yang Pemanfaatan teknologi yang meluas membuat manusiar (SDM) yang bagus, kondisi mas marakat organisasi terutama institusi berlomba menggunakan Indonesia pada umumnya yang belum melek teknologi teknologi untuk mencapai tujuannya salah satunya dan dengan sistem seperti ini akan semakin terjadi untuk mendapatkan kualitas peserta didik dalam proses persaingan antara sekolah yang populer (favorit) dan penerimaan siswa baru (PSB)[1].Penerimaan Siswa sekolah yang non-favorit, karena calon siswa yang Baru merupakan proses seleksi akademis calon siswa memiliki nilai bagus cenderung memilih sekolah "yang untuk menuju jenjang pendidikan yang lebih tinggi lebih punya nama"[2]. Dari hasil wawancara pada dalam tingkatan SMP, Sebenarnya Sistem Aplikasi Madrasah Tsanawiyah Negeri (MTsN) Jambat Balo Penerimaan Siswa Baru Online ini bagus jika didapatkan bahwa proses Penerimaan Siswa Baru diterapkan, semuanya akan jadi lebih praktis, canggih, (PSB) yang berlangsung belum menggunakan transparan sehingga dapat mengurangi terjadinya teknologi. Dimana calon siswa yang ingin mendaftar kecurangan dalam pendaftaran siswa baru, tapi sistem untuk menjadi siswa baru harus datang ke sekolah 
secara langsung dan menemui panitia Penerimaan hanya dari pemilik website. Bersifat dinamis apabila isi Siswa Baru (PSB) yang ada. Dalam hal ini panitia informasi website berubah-ubah, dan informasinya Penerimaan Siswa Baru (PSB) memberikan formulir interaktif dua arah berasal dari pemilik serta pengguna pendaftaran yang harus diisi oleh calon siswa. calon website. Website merupakan suatu koleksi dokumen siswa akan dimulai beserta pengumuman kelulusan. HTML (HypertText Markup Language) pribadi atau Setelah calon siswa mengikuti pelaksanaan tes dan perusahaan yang memuat informasi dalam Web Server dinyatakan lulus tahap selanjutnya adalah panitia (sistem komputer di suatu organisasi, yang berfungsi Penerimaan Siswa Baru (PSB) memberikan rincian sebagai server (suatu unit komputer yang berfungsi registrasi ulang, kemudian siswa yang telah lulus akan untuk menyimpan informasi dan untuk mengelola mulai belajar pada jam yang telah ditentukan.

jaringan komputer) untuk fasilitas World Wide Web

Perumusan masalah yang akan dibahas dalam atau Web, dan dapat diakses oleh seluruh pemakai penelitian ini adalah bagaimana "membangun website internet[6].

sistem penerimaan siswa baru (PSB) pada Madrasah Website merupakan dokumen HTML (HypertText Tsanawiyah Negeri (MTsN) Jambat Balo?".

Markup Language) yang memuat informasi dalam web

Dengan tujuan membangun website sistem server yang menggabungkan informasi data teks, data penerimaan siswa baru (PSB) yang dapat meningkatkan gambar diam atau gerak, data animasi, suara, dan pelayanan dan pemanfaatan teknologi informasi pada video.

Madrasah Tsanawiyah Negeri (MTsN) Jambat Balo.

\section{Tinjauan Pustaka}

\subsection{Rancang Bangun}

\subsection{Penerimaan Siswa Baru}

Penerimaan siswa baru merupakan salah satu proses yang ada di instansi pendidikan seperti sekolah yang

Rancang Bangun (desain) adalah tahap dari setelah berguna untuk menyaring calon siswa yang terpilih analisis dari siklus pengembangan sistem yang sesuai kriteria yang ditentukan oleh sekolah tersebut merupakan pendefinisian dari kebutuhan kebutuhan untuk menjadi siswa didiknya[7]. Pada umumnya fungsional, serta menggambarkan bagaimana suatu proses penerimaan siswa baru dilakukan melalui sistem dibentuk yang dapat berupa penggambaran, tahapan pendaftaran, tes seleksi, dan pengumuman perencanaan dan pembuatan sketsa atau pengaturan penerimaan siswa. Dalam penelitian ini penerapannya dari beberapa elemen yang terpisah ke dalam satu pada SMK Al-irsyad Tegal yang selama ini dilakukan kesatuan yang utuh dan berfungsi, termasuk secara manual atau sudah terkomputerisasi tetapi menyangkut mengkonfigurasikan dari komponen- menggunakan Microsoft Office Excel, yang komponen perangkat keras dan perangkat lunak dari memungkinkan masih banyak kekurangan data, suatu sistem[3]. Rancang Bangun atau perancangan penghitungan nilai tes secara manual yang sistem merupakan serangkaian prosedur untuk memungkinkan terjadinya kesalahan. Untuk itu menerjemahkan hasil analisis dari sebuah sistem ke dibutuhkan suatu sistem informasi yang dapat dalam bahasa pemrograman untuk mendeskripsikan membantu dalam proses penerimaan siswa baru. dengan detail bagaimana komponen-komponen sistem Penerimaan Siswa Baru (PSB) merupakan suatu proses diimplementasikan. Pengertian pembangunan atau administrasi yang terjadi setiap tahun untuk seleksi bangun sistem adalah kegiatan menciptakan sistem calon siswa berdasarkan nilai akademik agar dapat baru maupun mengganti atau memperbaiki sistem yang melanjutkan pendidikan pada jenjang yang lebih tinggi. telah ada baik secara keseluruhan[4].

Calon siswa yang dimaksud adalah siswa baru yang

Rancang bangun merupakan pendefinisian dari akan mendaftar pada jenjang SMP atau SMA/SMK kebutuhan-kebutuhan fungsional, serta negeri[8]. Apabila setiap tahunnya proses PSB selalu menggambarkan bagaimana suatu sistem dibentuk yang dilakukan secara manual pada masing-masing sub dapat berupa penggambaran, perencanaan dan rayon, maka akan menyebabkan berbagai kesulitan dari pembuatan sketsa atau pengaturan dari beberapa beberapa pihak yang terkait. Oleh karena itu, dibuatlah elemen untuk mendeskripsikan dengan detail sistem penerimaan siswa baru secara online atau yang bagaimana komponen-komponen sistem dikenal dengan nama PSB online [9]. Tujuan penerapan diimplementasikan.

\subsection{Website}

PSB online agar terciptanya transparasi penerimaan siswa baru dan kemudahan dalam seleksi siswa baru.

Penerimaan siswa baru adalah proses seleksi

Website atau situs dapat diartikan sebagai calon siswa baru guna mendapatkan calon siswa sesuai kumpulan halaman yang menampilkan informasi data dengan kriteria yang telah ditentukan oleh sekolah teks, data gambar diam atau gerak, data animasi, suara, untuk menjadi siswa didiknya.

video, atau gabungan dari semuanya, baik yang bersifat statis atau dinamis yang membentuk suatu rangkaian bangunan yang saling terkait dimana masing-masing dihubungkan dengan jaringan-jaringan halaman 3. Metode Penelitian

\subsection{Teknik Pengumpulan Data}

Teknik pengumpulan data yang penulis gunakan (hyperlink)[5]. Bersifat statis apabila isi informasi dalam penelitian ini adalah sebagai berikut: website tetap, tidak berubah dan isi informasinya searah a. Wawancara 
Dalam tahap ini penulis mengajukan beberapa Pertanyaan terhadap pihak yang terkait.

b. Dokumentasi

Dokumentasi merupakan metode yang digunakan dalam mencari data-data yang berkaitan dengan penelitian. Dokumentasi yang penulis kumpulkan dalam hal ini berupa rekaman suara.

c. Studi pustaka

Penulis mengumpulkan data-data melalui sejumlah jurnal, internet dan beberapa buku.

\subsection{Metode Pengembangan Sistem}

Dalam penelitian ini penulis menggunakan model pengembangan SDLC air terjun (waterfall) sering juga disebut model sekuensial linier (sequential linier) atau alur hidup klasik (classic life cyle). Model air terjun menyediakan pendekatan alur hidup perangkat lunak secara sekuensial atau terurut dimulai dari analisis, desain, pengkodean, pengujian, dan tahap pendukung (support)(Rossa A.S, 2014:28) [ $\left.{ }^{10}\right]$.

a. Analisis kebutuhan perangkat lunak

Proses pengumpulan kebutuhan dilakukan secara intensif untuk menspesifikasikan kebutuhan perangkat lunak agar dapat dipahami perangkat lunak seperti apa yang dibutuhkan oleh user. Spesifikasi kebutuhan perangkat lunak pada tahap ini perlu untuk di dokumentasikan.

b. Desain

Desain perangkat lunak adalah proses multi langkah yang fokus pada desain pembuatan program perangkat lunak termasuk struktur data, arsitektur, perangkat lunak, representasi antar muka, dan prosedur pengkodean. Tahap ini mentranslasi kebutuhan perangkat lunak dari tahap analisis kebutuhan kerepresentasi desain agar dapat diimplementasikan menjadi program pada tahap selanjutnya. Desain perangkat lunak yang dihasilkan pada tahap ini juga perlu di dokumentasikan.

c. Pembuatan kode program

Desain harus di translasikan kedalam program perangkat lunak. Hasil dari tahap ini adalah program komputer sesuai dengan desain yang telah dibuat pada tahap desain.

d. Pengujian

Pengujian fokus pada perangkat lunak secara dari segi lojik dan fungsional dan memastikan bahwa semua bagian sudah diuji. Hal ini dilakukan untuk meminimalisir kesalahan (error) dan memastikan keluaran yang dihasilkan sesuai dengan yang diinginkan.

e. Pendukung (support) atau pemeliharaan (maintenance)

Tidak menutup kemungkinan sebuah perangkat lunak mengalami perubahan ketika sudah dikirimkan ke user. Perubahan bisa terjadi karena adanya kesalahan yang muncul dan tidak terdeteksi saat pengujian atau perangkat lunak harus beradaptasi dengan lingkungan baru. Tahap pendukung atau pemeliharaan dapat mengulangi proses pengembangan mulai dari analisis spesifikasi untuk perubahan perangkat lunak yang sudah ada, tetapi tidak untuk membuat perangkat lunak baru.

\subsection{Rekayasa Web}

\subsubsection{Usecase Diagram}

Usecase diagram menggambarkan fungsionalitas yang diharapkan dari sebuah sistem. Sistem yang ditekankan adalah "apa" yang dilakukan sistem dan bukan "bagaimana" sebuah usecase mempersentasikan sebuah interaksi antara aktor dengan sistem. Diagram usecase secara umum menggambarkan interaksi antara admin, kepala sekolah, dan juga calon siswa.

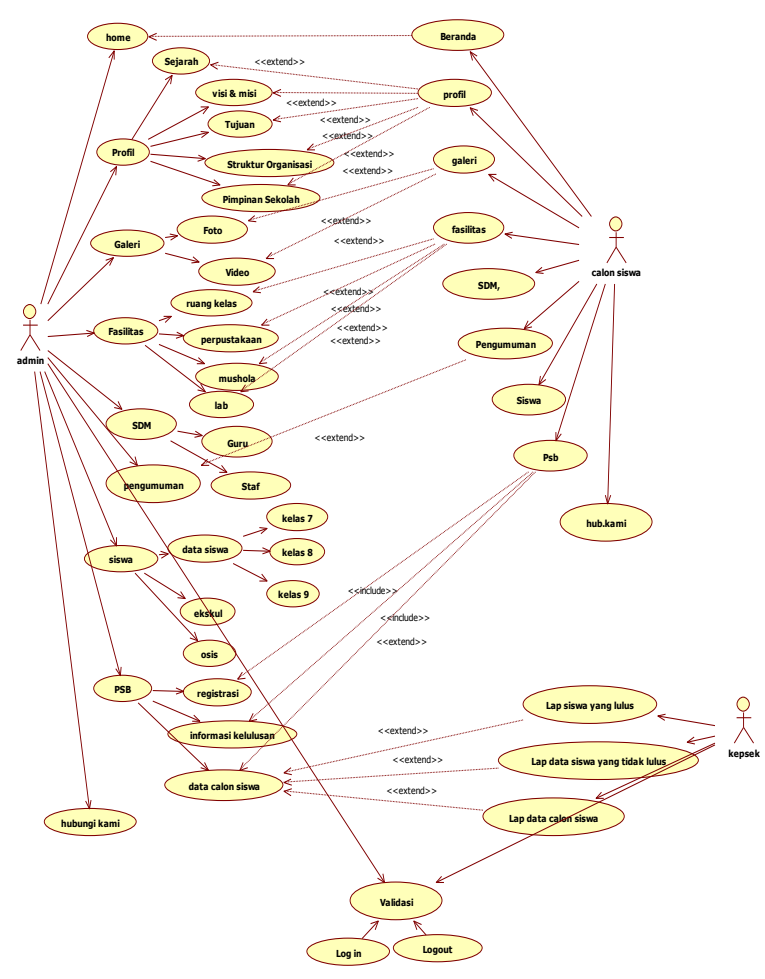

Gambar 1. Usecase Diagram

\subsubsection{Actifity Diagram}

Diagram ini menggambarkan interaksi antara calon siswa dan sistem, dimana calon siswa dapat melihat informasi mengenai penerimaan siswa baru. Calon siswa dapat melakukan registrasi secara langsung tanpa harus login ke sistem terlebih dahulu. 


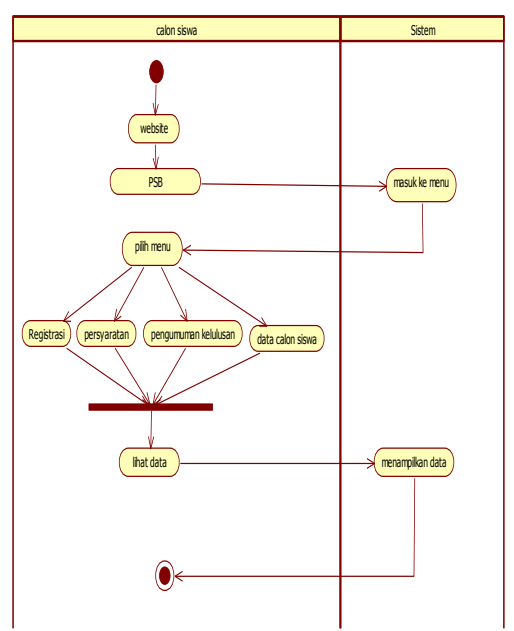

Gambar 2. Actifity Diagram

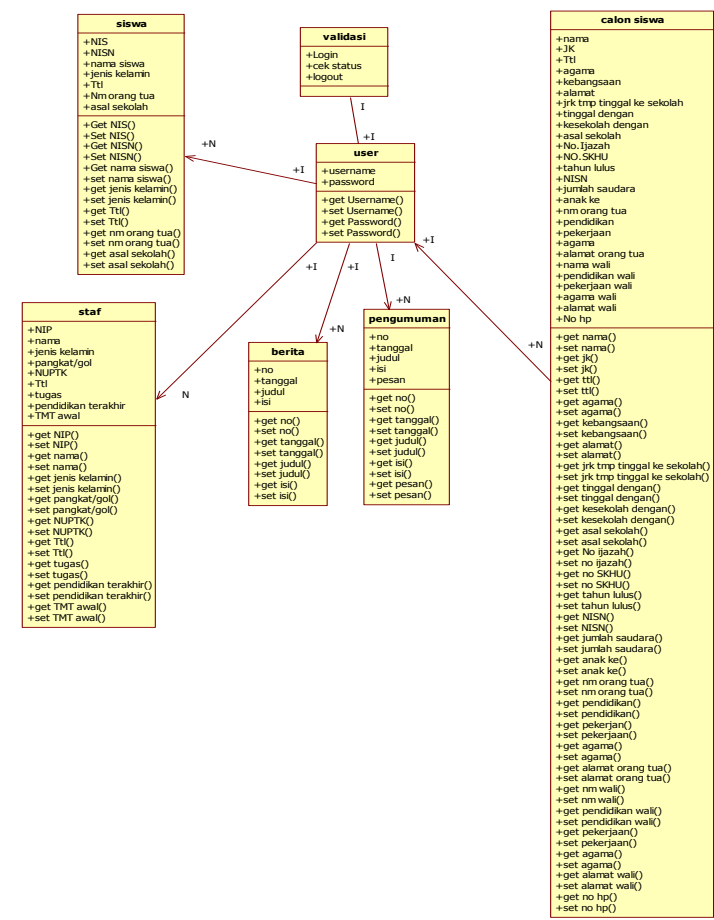

Gambar 4. Class diagram

melakukan registrasi melalui form yang disediakan, setelah itu sistem akan menyimpan data ke dalam database. Setelah data tersimpan sistem akan menampilkan form kartu ujian bagi calon siswa

\subsection{Desain Menu \\ 3.4.1 Menu Utama}

Tampilan menu utama ini adalah tampilan awal pada saat aplikasi dibuka, Saat berada di menu utama website, user akan di melihat beberapa menu pilihan seperti home, profil, galeri, fasilitas, Sumber Daya Manusia (SDM), pengumuman, siswa, Penerimaan Siswa Baru (PSB), dan menu hubungi kami/contact person pihak sekolah. Di menu utama ini juga terdapat menu login untuk admin dan kepala sekolah, informasi berita yang ada di madrasah, dan foto-foto kegiatan siswa/i yang ada di madrasah.

\subsubsection{Menu Pendaftaran}

Form ini menampilkan isi dari menu registrasi yang wajib diisi oleh calon siswa meliputi identitas siswa dan identitas orang tua siswa. Saat calon siswa mengakses form PSB, sistem juga akan menampilkan beberapa pilihan menu seperti menu daftar, menu pengumuman kelulusan/hasil tes serta menu data calon siswa. Ketika calon siswa meng-klik menu daftar maka akan tampil formulir yang wajib diisi sesuai dengan data yang di minta.

\subsubsection{Menu cetak kartu ujian}

Form ini menampilkan output dari data yang di input-kan siswa melalui form registrasi. Setelah calon

\subsubsection{Class Diagram}

Diagram kelas atau class diagram siswa selesai menginputkan data melalui form yang ada menggambarkan struktur sistem dari segi pendefinisian dan menyimpan data tersebut, kemudian sistem akan kelas-kelas yang akan dibuat untuk membangun menampilkan beberapa pilihan yaitu cetak kartu ujian system. Diagram kelas dibuat agar programmer dan cetak formulir. Saat calon siswa meng-klik form membuat kelas-kelas sesuai rancangan di dalam cetak kartu ujian maka akan ada pilihan untuk diagram kelas agar antara dokumentasi perancangan menyimpan ataupun langsung mencetak kartu. dan perangkat lunak sinkron.

Jurnal Ilmiah Binary STMIK Bina Nusantara Jaya

Vol. 01 No. 02 Tahun 2019, ISSN : 2657-2117 


\subsubsection{Cetak Formulir}

Form ini menampilkam halaman untuk data yang di minta.

mencetak Formulir calon siswa yang di input-kan melalui form pendaftaran. Sama seperti proses pada saat mencetak kartu, setelah calon siswa selesai menginputkan data melalui form yang ada dan menyimpan data tersebut, kemudian sistem akan menampilkan beberapa pilihan yaitu cetak kartu ujian dan cetak formulir. Saat calon siswa meng-klik form cetak kartu formulir maka akan ada pilihan untuk menyimpan ataupun langsung mencetak formulir.

\subsubsection{Informasi Kelulusan}

Tampilan ini menampilkan hasil dari test penerimaan siswa baru, untuk melihat hasil tes calon siswa harus menginputkan no pendaftaran yang di dapatkan pada saat melakukan pendaftaran secara online. No pendaftaran didapatkan secara otomatis berdasarkan data yang diinputkan oleh calon siswa.

\subsubsection{Menu data calon siswa}

Form ini menampilkan data-data yang diinputkan oleh calon siswa melalui form registrasi. Dalam form ini admin dan kepala sekolah dapat melihat jumlah calon siswa yang sudah terdaftar di dalam sistem.

\section{Hasil dan pembahasan}

\subsubsection{Tampilan Menu Utama}

Halaman utama merupakan halaman awal yang ditampilkan pada saat user membuka website sistem penerimaan siswa baru (PSB) pada Madrasah Tsanawiyah Negeri (MTsN) Jambat Balo. Halaman ini memuat menu login menu berita terbaru, dan menu navigasi ke halaman Home, Profile, Galeri, Fasilitas, Sumber Daya Manusia (SDM), Pengumuman, Siswa, Penerimaan Siswa Baru (PSB) dan contact. Tampilan halaman utama dapat dilihat pada gambar di bawah ini.

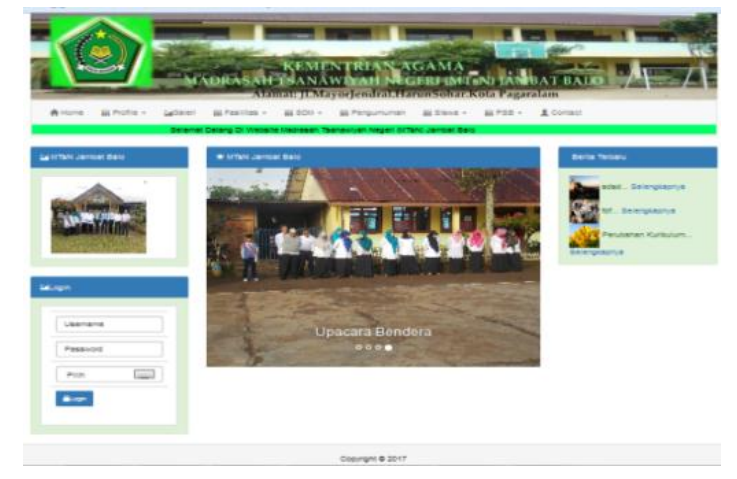

Gambar 5. Halaman menu utama

\subsubsection{Halaman Menu Pendaftaran}

Halaman ini menampilkan form pendaftaran bagi calon siswa baru. Pada saat calon siswa menjalankan sistem, sistem akan menampilkan menu utama dari website. Kemudian saat calon siswa mengakses form PSB, sistem juga akan menampilkan beberapa pilihan menu seperti menu daftar, menu pengumuman kelulusan/hasil tes serta menu data calon siswa. Ketika calon siswa meng-klik menu daftar maka

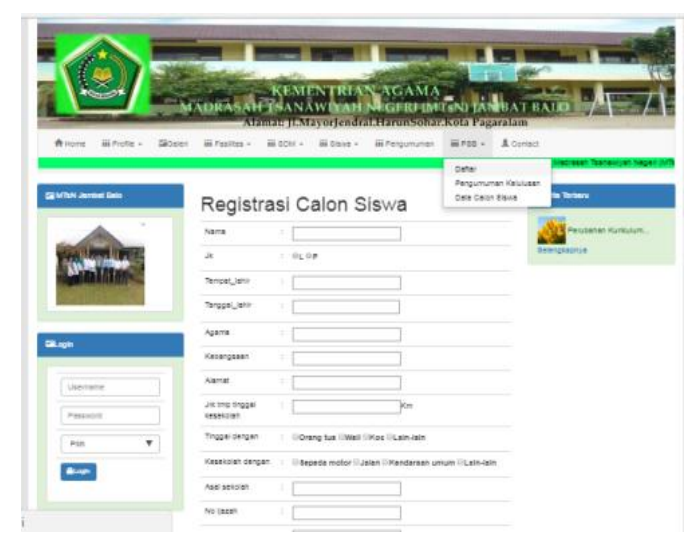

Gambar 6. Halaman menu pendaftaran

\subsubsection{Halaman Cetak Kartu}

Halaman ini menampilkan form cetak kartu ujian bagi calon siswa yang mendaftar. Setelah calon siswa selesai menginputkan data melalui form yang ada dan menyimpan data tersebut, kemudian sistem akan menampilkan beberapa pilihan yaitu cetak kartu ujian dan cetak formulir. Saat calon siswa meng-klik form cetak kartu ujian maka akan ada pilihan untuk menyimpan ataupun langsung mencetak kartu. Kartu ini juga berfungsi sebagai bukti bahwa calon siswa benar telah melakukan mendaftar secara online. Dengan catatan kartu ini harus di bawa pada saat akan melakukan test.

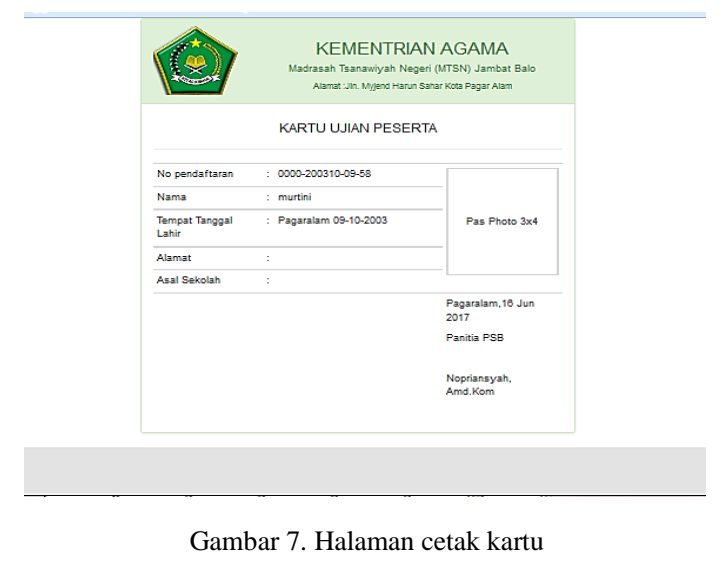

\subsubsection{Halaman cetak formulir}

Halaman ini menampilkan hasil dari proses pendaftaran berupa data calon siswa yang telah melakukan pendaftaran secara online. Sama seperti proses pada saat mencetak kartu, setelah calon siswa selesai menginputkan data melalui form yang ada dan menyimpan data tersebut, kemudian sistem akan menampilkan beberapa pilihan yaitu cetak kartu ujian dan cetak formulir. Saat calon siswa meng-klik form cetak kartu formulir maka akan ada pilihan untuk menyimpan ataupun langsung mencetak formulir. 


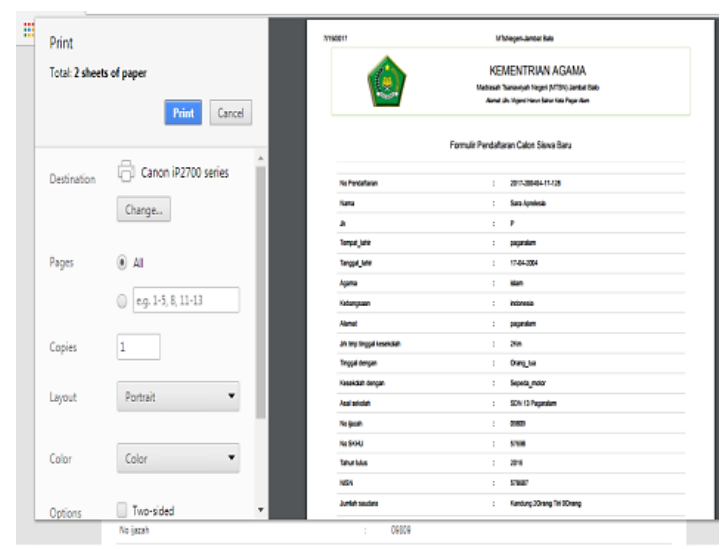

Gambar 8. Halaman cetak formulir

\subsubsection{Halaman informasi kelulusan}

Pada halaman ini akan menampilkan hasil test dari calon siswa, , untuk melihat hasil tes calon siswa harus menginputkan NISN yang di dapatkan calon siswa dari SD. Kemudian pada saat NISN di inputkan selanjutnya sistem akan menampilkan hasil dari tes yaitu lulus dan tidak lulus dilihat dari nilai yang diperoleh setelah tes, hasil harus di cetak sebagai bukti pada saat daftar ulang.

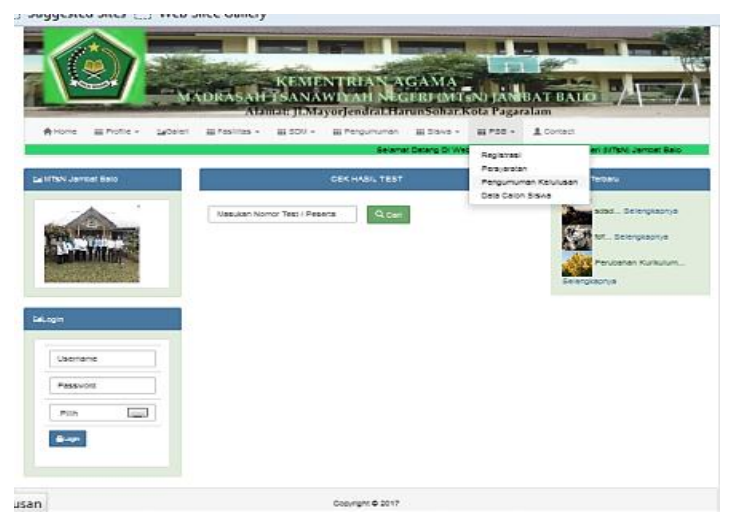

Gambar 9. Halaman informasi kelulusan

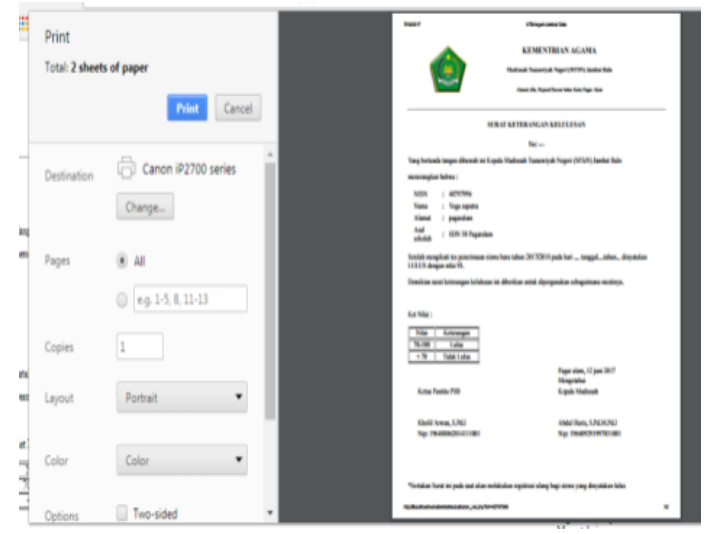

Gambar 10. Halaman cetak hasil kelulusan

\subsubsection{Halaman Data Calon Siswa}

Pada halaman ini akan menampilkan informasi berupa data calon siswa yang telah melakukan registrasi secara online. Dalam form ini admin dan kepala sekolah dapat melihat jumlah calon siswa yang sudah terdaftar di dalam sistem.

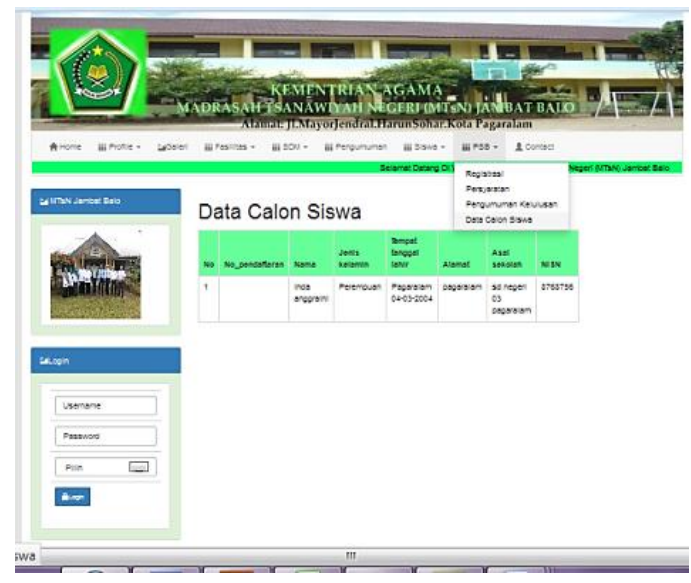

Gambar 11. Halaman data calon siswa

\section{Kesimpulan}

Dalam penelitian ini telah diuraikan tahapantahapan apa saja yang telah dilakukan oleh penelit dalam merancang dan membangun website sistem penerimaan siswa baru (PSB) pada Madrasah Tsanawiyah Negeri (MTsN) Jambat Balo, maka peneliti dapat menyimpulkan beberapa hal, yaitu:

a. Website sistem penerimaan siswa baru (PSB) pada Madrasah Tsanawiyah Negeri Jambat Balo adalah sarana untuk mengolah data calon siswa yang melakukan registrasi untuk menjadi siswa di Madrasah dan mempermudah calon siswa dalam meakukan pendaftaran.

b. Daftar Menu yang mudah dipahami sangat diperlukan agar calon siswa mudah dalam mengoperasikan sistem.

\section{Daftar Rujukan}

[1] Chandra, T. (2015). Perancangan Sistem Informasi Pendaftaran Mahasiswa Baru Pada Perguruan Tinggi X Berbasis Web.Jurnal Times, Vol.4 No 2.

[2] Miftahus Sholihin, S. M. (2014). Sistem Penerimaan Peserta Didik Baru Berbasis Web (Online) Di SMK Muhammadiyah 7 Kedungpring Lamongan. Jurnal Teknika, Vol.6 No.1.

[3] Devina, A. (2013). Analisis dan Rancang Bangun Sistem Informasi Pengolahan Data Pembayaran Kredit Rumah Berjangka Pada PT Pulau Jaya Abadi Palembang Menggunakan Pemrograman Delphi 2007 dan SQL Server 2008. journal sistem informasi, Vol.12 No.2.

[4] Selvia Dwi Rahmawati, B. L. (2013). Rancang Bangun Sistem Informasi Spasial, Vol.6 No.2.

[5] Anggiani Septima Riyadi, E. R. (2012). Perancangan Sistem Informasi Berbasis Web Subsistem Guru di Sekolah Pesantren Persatuan Islam 99 RancangBango. Jurnal Algoritma, Vol.9.

[6] Basuki, M. A. (2009). Analisa Website Universitas Muria Kudus. Jurnal Sains. ISSN 1979-6870

Jurnal Ilmiah Binary STMIK Bina Nusantara Jaya

Vol. 01 No. 02 Tahun 2019, ISSN : 2657-2117 
[7] Ramadhani, N. A. (2011). Pembangunan Sistem Informasi Penerimaan Siswa Baru Di Sekolah Menengah. Journal Speed - Sentra Penelitian Engineering dan Edukasi,

[8] Pusparani Sholikhah, K. G. (2009). Rancang Bangun Sistem Informasi Penerimaan Siswa Baru Online. Journal Sistem Informasi .

[9] Putri, L. D. (2014). Perancangan Sistem Informasi Penerimaan Siswa Baru Pada Sekolah Menengah Kejuruan Negeri 3 Pacitan. Indonesian Journal on Networking and Security.

[10] Rossa A.S, M. (2014). Rekayasa Perangkat Lunak Bandung: Informatika Bandung. 